
\title{
R Research Souture \\ Effective Interventions on Health Effects of Chinese Rural Elderly under Heat Exposure
}

\author{
Yujia Huang \\ Nanjing University \\ Ting Zhang \\ Nanjing University \\ Jianing Lou \\ Nanjing University \\ Peng Wang \\ Jiangsu University \\ Lei Huang ( $\nabla$ huanglei@nju.edu.cn ) \\ Nanjing University
}

\section{Research Article}

Keywords: high temperature, health effect, comprehensive evaluation, intervention, rural elderly

Posted Date: February 24th, 2022

DOI: https://doi.org/10.21203/rs.3.rs-1368052/v1

License: (c) (1) This work is licensed under a Creative Commons Attribution 4.0 International License. Read Full License 


\section{Effective Interventions on Health Effects of Chinese Rural Elderly}

2 under Heat Exposure

3 Yujia Huang ${ }^{1}$, Ting Zhang ${ }^{1}$, Jianing Lou ${ }^{1}$, Peng Wang $^{2}$, Lei Huang ${ }^{1 *}$

4

$5 \quad{ }^{1}$ State Key Laboratory of Pollution Control and Resource Reuse, School of the

6 Environment, Nanjing University, Xianlin Campus, 163 Xianlin Avenue, Nanjing

$7 \quad 210023$, China.

$8{ }^{2}$ Faculty of Civil Engineering and Mechanics, Jiangsu University, Zhenjiang 212013,

9 China.

10

$11{ }^{*}$ Lei Huang, huanglei@nju.edu.cn, 163 Xianlin Avenue, Qixia District, Nanjing City,

12 Jiangsu Province, China.

13

14

15

16

17

18

19

20

21

22 


\section{Abstract:}

24 Background: Due to climate change, the heatwave has become a more serious public

25 health threat with aging as an aggravating factor in recent years. There is a pressing

26 need to detect the most effective prevention and response measures. However, the

27 specific health effects of interventions have not been characterized on an individual

28 scale.

29 Method: In this study, an intervention experiment was designed to explore the health

30 effects of heat exposure at the individual level and assess the effects of different

31 interventions based on a comprehensive health sensitivity index (CHSI) in Xinyi, China.

32 Forty-one subjects were recruited randomly, and divided into one control group and

33 three intervention groups. Interventions included education (Educate by lecturing,

34 offering relative materials, and communication), subsidy support (offer subsidy to

35 offset the cost of running air conditioning), and cooling-spray (install a piece of cooling-

36 spray equipment in the yard).

37 Results: Results showed that systolic blood pressure (SBP) and deep sleep duration

38 (DSD) were significantly affected by short-term heat exposure, and the effects could be

39 alleviated by three types of interventions. The estimated CHSI indicated that the

40 effective days of the education group were longer than other groups, while the lower

41 CHSI of the subsidy group showed lower sensitivity than the control group.

42 Conclusions: Education and subsidy support can help reduce the effect of heat

43 exposure efficiently. These findings provide feasible implementation strategies to 
44 optimize Heat-health action plans and evaluate the intervention performance.

45 Keywords: high temperature, health effect, comprehensive evaluation, intervention, 46 rural elderly

47 


\section{Introduction}

Along with global climate change, the average surface temperature has increased more than $1{ }^{\circ} \mathrm{C}$ above the pre-industrial level continuously [1-3]. Heatwave is a typical

51 extreme temperature issue and has become a potential risk to public health [4-7].

52 Heatwaves not only lead to death but also raise the morbidity of respiratory-diseases

53 and cardiovascular diseases, which contribute to the increment of mortality [8-11].

54 Based on researches with different spatial scales, it was found that the frequency of 55 global heatwaves increased by 2.7 times every ten years (1981-2010), while the amount 56 of extreme warming events in China increased by 6.79 days/decade (1961-2017)[12, 13]. It is convinced that the number of high-temperature days shows a decreasing trend in central and an increasing trend in northwest and southeast, based on an analysis of high-temperature characteristics over fifty years in China[14, 15]. Though there are periodical fluctuations, the frequency, intensity, duration, and area of heatwave show a

61 climbing trend by and large[16].

The elderly have been recognized as the most vulnerable people to heatwave [17-

63 19]. In the past decades, the heat-related mortality of the elderly ( $\geqslant 65$ years) has 64 increased by $53.7 \%$ [20]. Particularly, the heat exposure of the elderly in China has come up to 2.2 million person-days, representing some 13 additional days of heatwaves experienced[20,21]. When exposed to high temperatures, people will take steps to cool themselves through sweating automatically [22]. However, the elderly's poor 
Owing to income and chronic diseases, rural residents are more likely to be affected[23]. In addition, it is difficult for older people to accept the heat-related recommendations,

71 especially for those who are over 75 years old and low-educated[24]. Thus, it is a 72 considerable challenge to alleviate the heat health risks of the elderly.

73 Evidence suggests that the heat health warning system and education can reduce 74 heat-related death rates by improving residents' risk perception[25-28]. The effectiveness of an intervention is mainly measured by the reductions in high temperature-related morbidity and mortality, or by the improvement in public response behavior [29-31]. However, there are no researches that have measured the potential impact or benefit of the actions in reducing the incidence of high temperature-related morbidity. Heart rate and blood pressure are essential signals when the human body becomes disordered. Thus, they are used to partly explain the mechanism of temperature-related cardiovascular admission/death[32, 33]. Though the long-term relationships between temperature change and heart rate or blood pressure have been figured out in previous studies, the effect of interventions on individual health is still unclear.

Along with the threat of global warming and population aging, it is challenging to struggle with high temperatures. The usage of air conditioning can reduce subjective thermal discomfort, but contributes to more global greenhouse gas emissions simultaneously [34]. Therefore, there is a pressing need to explore sustainable and 
89 effective intervention measures. However, the previous intervention, like the warning

90 system, fails to evaluate the effect at individual scale[35]. To the best of our knowledge,

91 there have been few reports on the relationships between interventions and health

92 indicators about the elderly in a realistic condition. Additionally, various heat-related

93 influences on physical indicators make it challenging to assess the effectiveness by one

94 metric. Thus, it is necessary to explore individual-based interventions and evaluate the

95 effectiveness through a proper approach. We conducted an intervention experiment

96 involving the Chinese rural elderly in 2019. Though we have explored the intervention

97 effect on behavior and perception in previous research, the relationship between

98 physical metrics and intervention is unclear[36]. Specifically, the objectives of this

99 research are 1) to characterize six metrics' variation under heat exposure; 2) to evaluate

100 the protective effect of three interventions with a comprehensive index; 3) to explore

101 the possibility of a sustainable intervention method. Based on the research, the

102 governments and institutions could develop and improve a more targeted

103 implementation to reduce heat-related health risks for the rural elderly.

\section{2. Material and Methods}

\section{$105 \quad 2.1$ Study Design}

106 Xinyi (Figure 1) is an inland area located in the north part of Xuzhou, Jiangsu

107 Province, one of the provinces that suffered heatwaves with the highest frequency and

108 intensity typically observed in China [36-38]. Based on previous studies, the heat health 
110 the survey in the rural area of Xinyi city. There are over eight hundred elderly people

111 in the selected area. With the support from the local Chinese Center for Disease Control

112 and Prevention (China CDC), we selected one hundred elderly people by simple

113 random sampling. Eighty of the one hundred elderly expressed the willingness to attend

114 this study. We excluded thirty-seven elderly people with primary diseases such as

115 hypertension, diabetes, and other chronic diseases, which make it difficult to identify

116 the main factors of health metrics' changes. Forty-four elderly people were recruited

117 for the following intervention study. After controlling the variation in basic

118 characteristics, the participants were randomly divided into control group, education

119 group, subsidy support group, and cooling-spray group. Three participants dropped out

120 for personal reasons during the survey and forty-one were left for finally analyses. For

121 education intervention, participants took lectures (July $\left.21^{\text {st }}\right)$, read heat-related materials

122 (July $22^{\text {nd }}$ ), and communicated with our team members (July $23^{\text {th }}$ ), respectively.

123 Participants of the subsidy support group received 10 yuan (based on local electric

124 charge, average cost on air-conditioning use for one day is about 10 yuan) each day to

125 offset the cost of air conditioning use for five consecutive days. Cooling-spray

126 equipment was installed in the yard of each participant from the cooling-spray group.

127 The equipment was set to spray 5 min every half hour from 9.am to 5.pm to cool the

128 external environment house. The more specific information about the intervention

129 experimental design and device in use has been described by Lou et al. (2021). 
131 heat wave[40, 41]. The $90^{\text {th }}$ percentile temperature in Xinyi is $32^{\circ} \mathrm{C}$. The survey lasted 132 from $17^{\text {th }}$ July, 2019 to $25^{\text {th }}$ July, 2019. To characterize the variation after the 133 intervention, we defined the period before intervention $\left(17^{\text {th }} \mathrm{July}-20^{\text {th }} \mathrm{July}\right)$ as period 1340 , and each day of intervention from $21^{\text {st }}$ July to $25^{\text {th }}$ July as day 1 , day 2, day 3, day 4, 135 and day 5 , respectively. The data in period 0 represented the baseline of the participants.

136 Three intervention groups were assigned to receive the education, subsidy, and cooling137 spray from day 1 to day 5, while the control group did not undergo any intervention 138 measures throughout this survey. The content of the study design and statistical analysis 139 is shown in Figure 2.

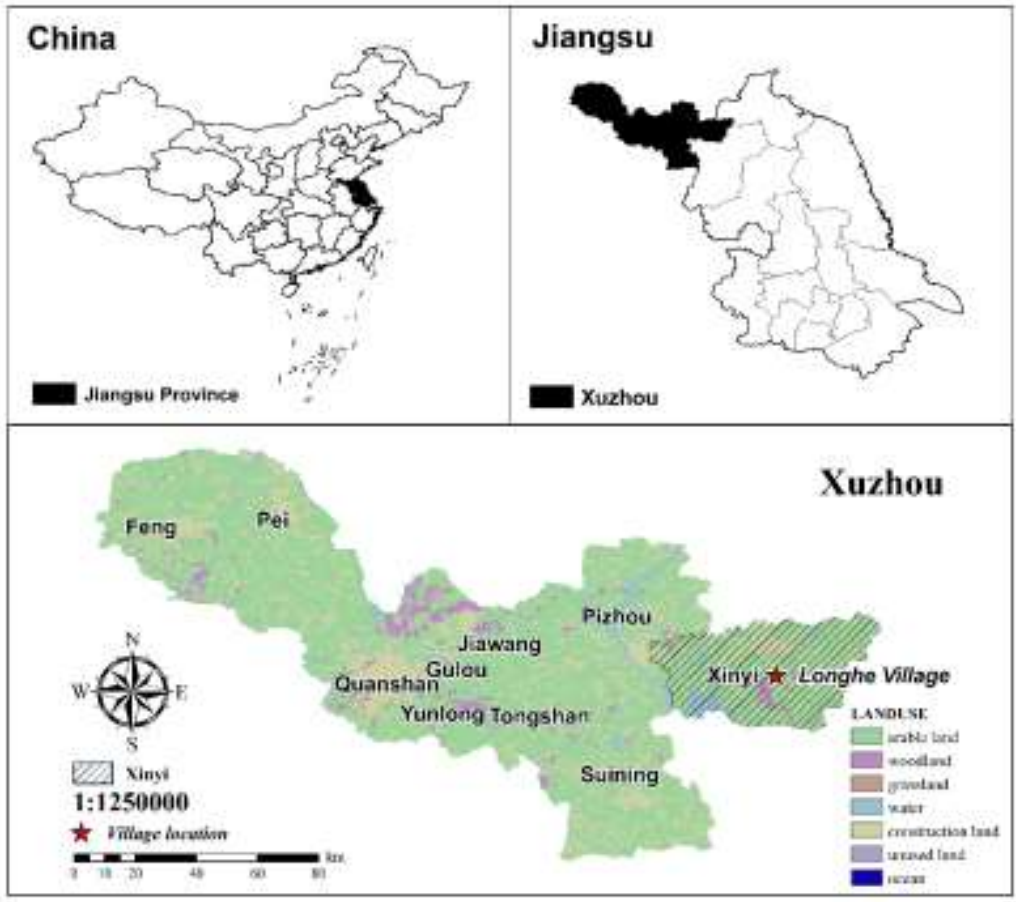




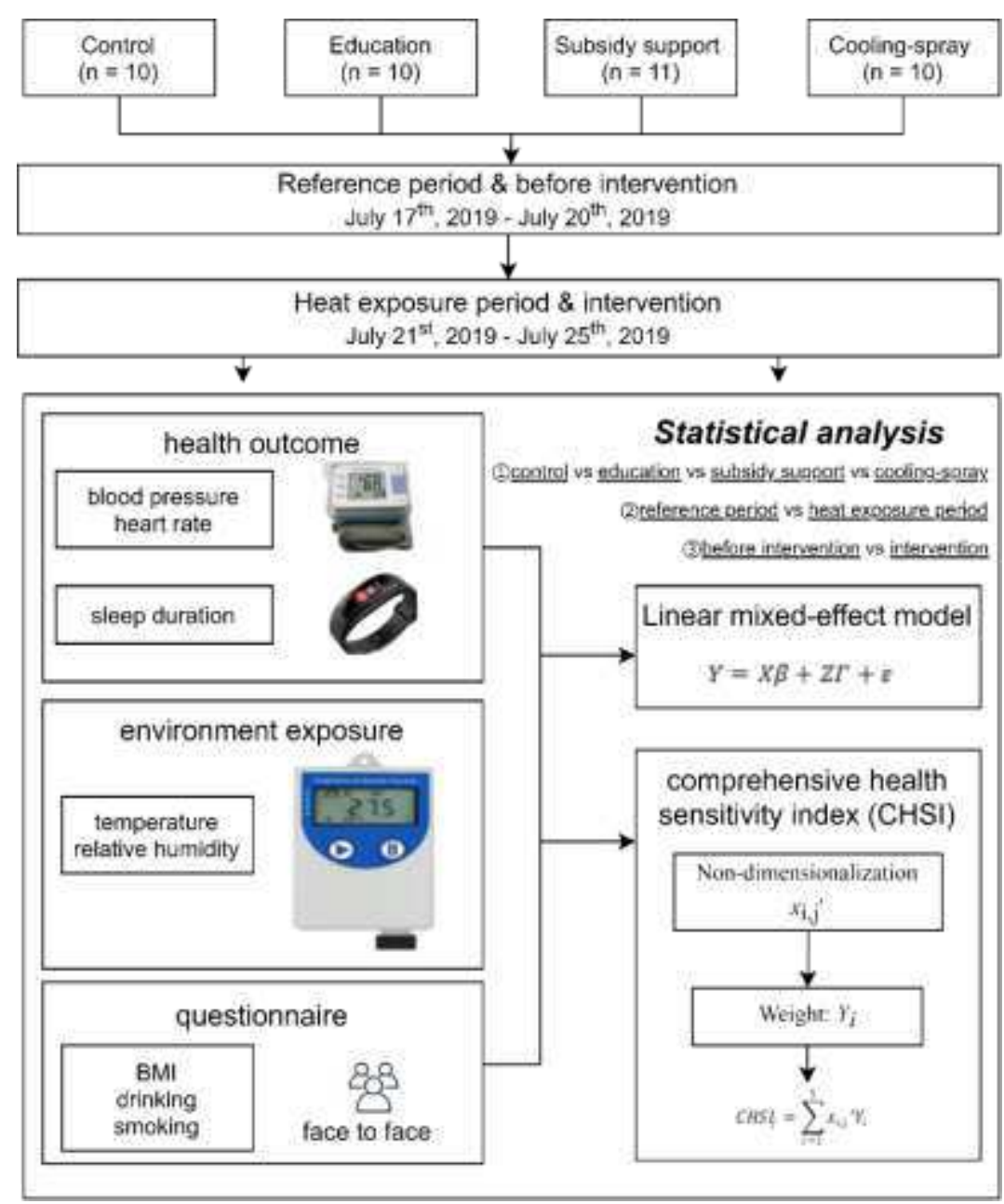

Figure 2 The flowchart of the methodology

\subsection{Health Outcome and Exposure Measures}

A wrist blood pressure monitor was used to measure the blood pressure and heart

147 rate of the participant. The participants would sit for 3-5 minutes before monitoring to

148 decrease the effects of activity status. Each metric was measured three times every

149 morning during the whole period. Daily sleep duration was monitored by a smart band

150 worn by the participant on his/her hand. The sleep duration had been divided into total

151 sleep duration (TSD), deep sleep duration (DSD), and light sleep duration (LSD) for

152 describing different sleep states 
154 placed upper chest and used to measure individual temperature and humidity exposure

155 data every five seconds. The sensor has a temperature accuracy of $\pm 0.3{ }^{\circ} \mathrm{C}$ and a

156 measurement range from $-20{ }^{\circ} \mathrm{C}$ to $+65{ }^{\circ} \mathrm{C}$. The relative humidity accuracy of the

157 sensor is $\pm 2 \% \mathrm{RH}$ (https://www.renkeer.com/). Participants were required to wear the

158 equipment all day (0:00-24:00) from July $17^{\text {th }}$ to July $25^{\text {th }}$.

\subsection{Statistical Analysis}

Multiple measurements of the same object in different periods bring out the

161 autocorrelation between repeated measurement data. The linear mixed-effects model

162 overcomes the weakness that cannot be analyzed when the response variable has the

163 characteristics of non-independence and heteroscedasticity. The random effect term was

164 introduced to expand the application range of the linear model.

$$
Y=X \beta+Z \Gamma+\varepsilon
$$

166 where $Y$ is the dependent variable, $X$ is the matrix of the fixed-effect independent

167 variable, $\beta$ is the parameter vector of the independent variable, $Z$ is the design matrix

168 of random effects, $\Gamma$ is the parameter vector of the random effect, and $\varepsilon$ is the residual

169 random error vector.

170 In this study, the "lme4" software package in R software was used to construct a

171 mixed effect model to evaluate the impact of an intervention on outcome variables,

172 including blood pressure, heart rate, and sleep duration. We fitted the models with or

173 without these variables respectively and compared the fit using the Akaike Information 
174 Criterion (AIC). Health metric values were dependent variables, group (control group,

175 education group, subsidy-support group, cooling-spray group), period (before the

176 intervention, each day of intervention) and the interaction items between group and

177 period were fixed effects, and personal temperature exposure, relative humidity, BMI,

178 whether drinking, whether smoking were covariates. Variables were controlled, and the

179 participant's id was set to a random effect. The changes of health metrics among days

180 were calculated based on the results of the linear mixed-effects model. The "emmeans"

181 package in the $\mathrm{R}$ software was used to compare the value of metrics between

182 intervention groups and control groups from day 1 to day 5, and calculate the

183 differences.

\section{$184 \quad 2.4$ Comprehensive Health Sensitivity Index (CHSI)}

Each physical metric could reflect the body's adjustment to temperature change.

186 However, most physical metrics, like blood pressure, have a threshold in medicine [42].

187 When the metrics are within the threshold, a person is considered at a low risk to get an

188 unhealthy outcome. When extreme weather events such as heatwaves occur, the metrics

189 will fluctuate due to the regulation of the body, even beyond the threshold range. All

190 changes should be taken into consideration when choosing a better intervention.

191 Therefore, we attempted to characterize the sensitivity level of residents to temperature

192 changes through the fluctuation of metrics, defining it as a comprehensive health

193 sensitivity index (CHSI). When the health index fluctuates greatly, it is considered that

194 the residents' health sensitivity is high. In this study, CHSI was made up of heart rate, 

blood pressure, and sleep duration.

The specific steps are as follows:

(1) Non-dimensionalization data processing metric:

$$
x_{i . j}^{\prime}=\frac{\left|x_{i, j}-x_{i, 0}\right|}{x_{i, 0}}
$$

The variable $x_{i, j}$ represents the average data of the $i^{\text {th }}$ metric for each group on the $\mathrm{j}^{\text {th }}$ day of the intervention. $x_{i, 0}$, which is the mean value of the $\mathrm{i}^{\text {th }}$ metric in period 0. $x_{i, j}{ }^{\prime}$ represents the data of the $\mathrm{i}^{\text {th }}$ metric on the $\mathrm{j}^{\text {th }}$ day during intervention after nondimensionalization processing.

(2) Calculating weights for each of the components of the CHSI, $Y_{i}$

We aggregate the metrics for the first time (Equation 2), in which the weight $\Omega_{i}$ is determined by the AHP (Analytic Hierarchy Process). The time vector $w_{j}$ was calculated by Equation 3. The second aggregation was performed by inducing the TOWA operator in terms of time (Equation 4) [43, 44]. Then Equation 5 was used to calculate the metric's weight $Y_{i}$.

$$
b=\sum_{i=1}^{5} x_{i j}^{\prime} \Omega_{i}
$$


216 where $b$ is the evaluation value of each evaluation object in the specific period; $\Omega_{i}$ is

217 the subjective weight of the $\mathrm{i}^{\text {th }}$ metric; $\lambda$ is the "time degree"; $W=\left(w_{1}, w_{2}, \cdots, w_{5}\right)^{\mathrm{T}}$ is

218 the time weight vector; $X_{i j}$ is the result of the second aggregation;

219 (3) Calculation of CHSI

$$
\text { CHSI }_{j}=\sum_{i=1}^{5} x_{i, j}{ }^{\prime} Y_{i}
$$

221 where $\mathrm{CHSI}_{\mathrm{j}}$ represents the comprehensive result of each day during the intervention 222 period.

\section{Results}

Table 1 showed a detailed summary of all participants. The age of each group ranged from 57.9 to 60.1 , and the proportion of air conditioning users was higher than $80 \%$ in each group. No significant differences have been observed in baseline characteristics among groups as shown in Table 1 ( $\mathrm{p}$-value $>0.05)$. The maximum air temperature $\left(\mathrm{AT}_{\max }\right)$ in each period and the average individual exposure temperature of each group were in Table S1, and the air temperature range has been showed in Figure $\mathrm{S} 1$. The $\mathrm{AT}_{\max }$ of the intervention period (July $21^{\text {st }}$ to July $25^{\text {th }}$ ) were higher than $32^{\circ} \mathrm{C}$,

231 which means that the intervention was conducted during a heat wave. Compared with

232 the control group, a decreasing trend has been observed in personal average temperature 233 in intervention groups during the heatwave. 
Table 1 Baseline characteristics of the study population by groups

\begin{tabular}{|c|c|c|c|c|c|}
\hline Characteristics & $\begin{array}{l}\text { Control } \\
\text { Group }\end{array}$ & $\begin{array}{l}\text { Education } \\
\text { Group }\end{array}$ & $\begin{array}{c}\text { Subsidy } \\
\text { Support } \\
\text { Group }\end{array}$ & $\begin{array}{l}\text { Spray- } \\
\text { cooling } \\
\text { Group }\end{array}$ & $\begin{array}{c}\text { p- } \\
\text { value }\end{array}$ \\
\hline Number & 10 & 10 & 11 & 10 & - \\
\hline \multicolumn{6}{|l|}{ Sex } \\
\hline Male & 4 & 3 & 5 & 4 & 0.910 \\
\hline Age & $57.9 \pm 6.57$ & $58.4 \pm 6.42$ & $68.8 \pm 6.66$ & $60.1 \pm 7.40$ & 0.881 \\
\hline \multicolumn{6}{|l|}{ Education } \\
\hline Low level & 6 & 6 & 8 & 6 & \multirow{2}{*}{0.917} \\
\hline Medium level & 4 & 4 & 3 & 4 & \\
\hline \multicolumn{6}{|l|}{ Family annual } \\
\hline $\begin{array}{l}\text { income per } \\
\text { capita(yuan) }\end{array}$ & $15330 \pm 9777$ & $15690 \pm 8442$ & $13982 \pm 4020$ & $15050 \pm 7920$ & 0.967 \\
\hline \multicolumn{6}{|l|}{$\begin{array}{l}\text { Air-conditioning } \\
\text { ownership }\end{array}$} \\
\hline Yes & 8 & 9 & 10 & 8 & \multirow{2}{*}{0.825} \\
\hline No & 2 & 1 & 1 & 2 & \\
\hline \multicolumn{6}{|l|}{ Physical condition } \\
\hline Moderate & 3 & 4 & 3 & 4 & \multirow{2}{*}{0.894} \\
\hline Healthy & 7 & 6 & 8 & 6 & \\
\hline BMI & $24.30 \pm 3.56$ & $24.11 \pm 1.75$ & $24.94 \pm 3.36$ & $21.97 \pm 2.62$ & 0.160 \\
\hline \multicolumn{6}{|l|}{ Smoking } \\
\hline YES & 6 & 4 & 4 & 6 & \multirow[t]{2}{*}{0.600} \\
\hline NO & 4 & 6 & 7 & 4 & \\
\hline \multicolumn{6}{|l|}{ Drinking } \\
\hline YES & 1 & 2 & 2 & 3 & \multirow[t]{2}{*}{0.750} \\
\hline NO & 9 & 8 & 9 & 7 & \\
\hline
\end{tabular}

237 The format of data in the table is Mean \pm standard deviation. "Moderate" physical condition

238 means slightly worse than healthy.

\subsection{Control Group}

241 Diastolic Blood Pressure (DBP) of the control group showed an insignificant increase

242 in the first 4 days and the maximal level was $3.73 \mathrm{mmHg}$. The Systolic Blood Pressure

243 (SBP) in the control group significantly increased on day 1 and day 2, rising by 5.62 
$\mathrm{mmHg}(95 \% \mathrm{CI}: 1.77-9.46 ; \mathrm{p}=0.01)$ and $5.33 \mathrm{mmHg}(95 \% \mathrm{CI}: 1.05-9.60 ; \mathrm{p}=0.02)$, respectively. After day 3, the changes of SBP became more moderate.

249 from $31.6^{\circ} \mathrm{C}$ (July $20^{\text {th }}$ ) to $34.7^{\circ} \mathrm{C}$ (July $21^{\text {st }}$ ). However, there was no significant difference between groups or periods.

insignificant upward trend during the intervention period.
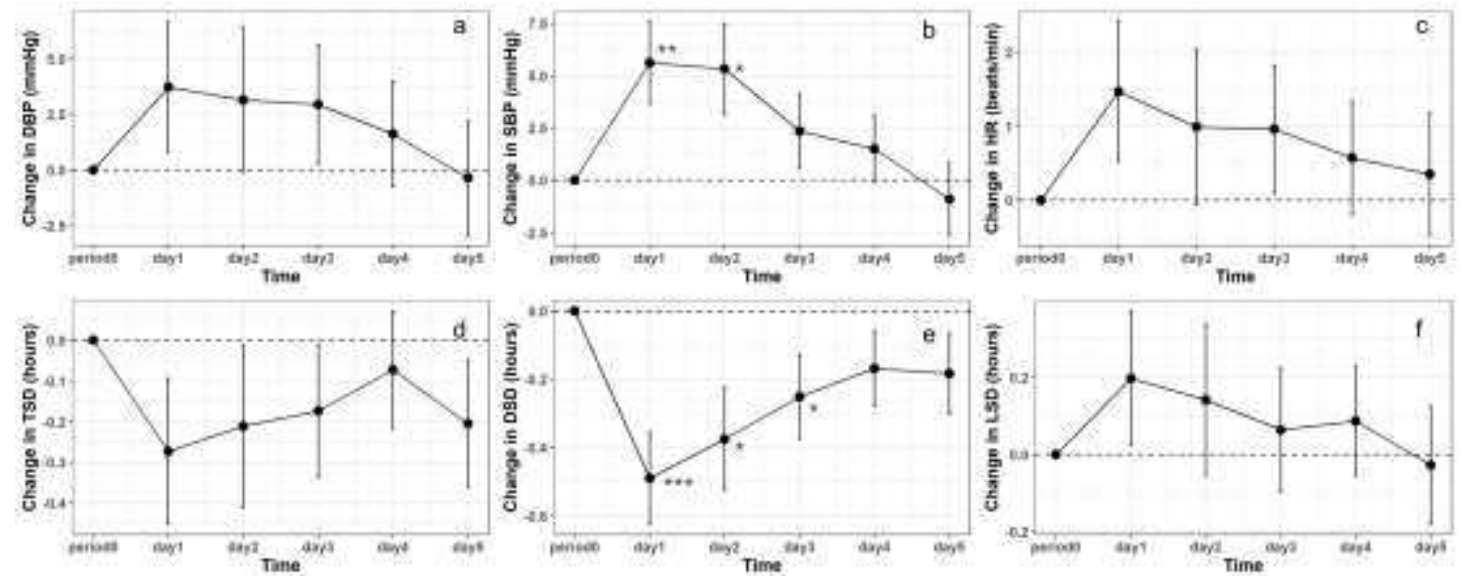

Figure 3 Changes in Different Health Metrics of Control Group from Baseline (period 0) 


\subsection{Intervention Groups}

The DBP of the education group changed slightly during the whole period, while the DBP of the cooling-spray group and the subsidy support group had a similar

264 increasing trend as the control group (Figure 4). There was no significant difference 265 observed in DBP in these three groups during the intervention. In the education group 266 and the subsidy support group, SBP stayed at a relatively stable level throughout the

267 entire period. The trend of SBP of the cooling-spray group was similar to that of the 268 control group. There was a significant increase of $3.14 \mathrm{mmHg}(95 \% \mathrm{CI}: 0.19,6.09$; $269 \mathrm{p}=0.04$ ) on day 1 in SBP for the cooling-spray group. The SBP level then gradually 270 declined and became steady. Figure 5 shows the differences in blood pressure between 271 the control group and different intervention groups. Compared with the control group, 272 SBP of the education group was $8.04 \mathrm{mmHg}(95 \% \mathrm{CI}:-12.90,-3.18 ; \mathrm{p}=0.01)$ and 8.34 $273 \mathrm{mmHg}(95 \% \mathrm{CI}:-13.20,3.48 ; \mathrm{p}=0.01)$ lower on day 1 and day 2 , respectively.
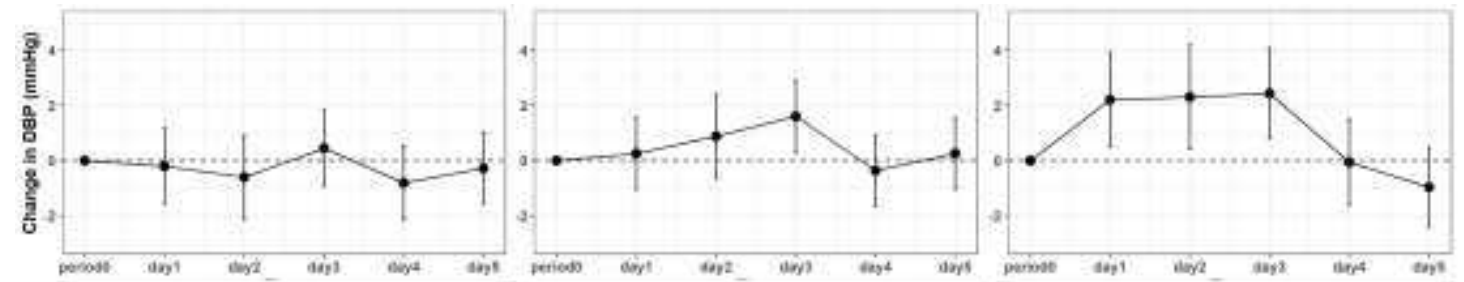

Figure 4 Changes in Blood Pressure of Three Intervention Groups from Baseline (period 0) 

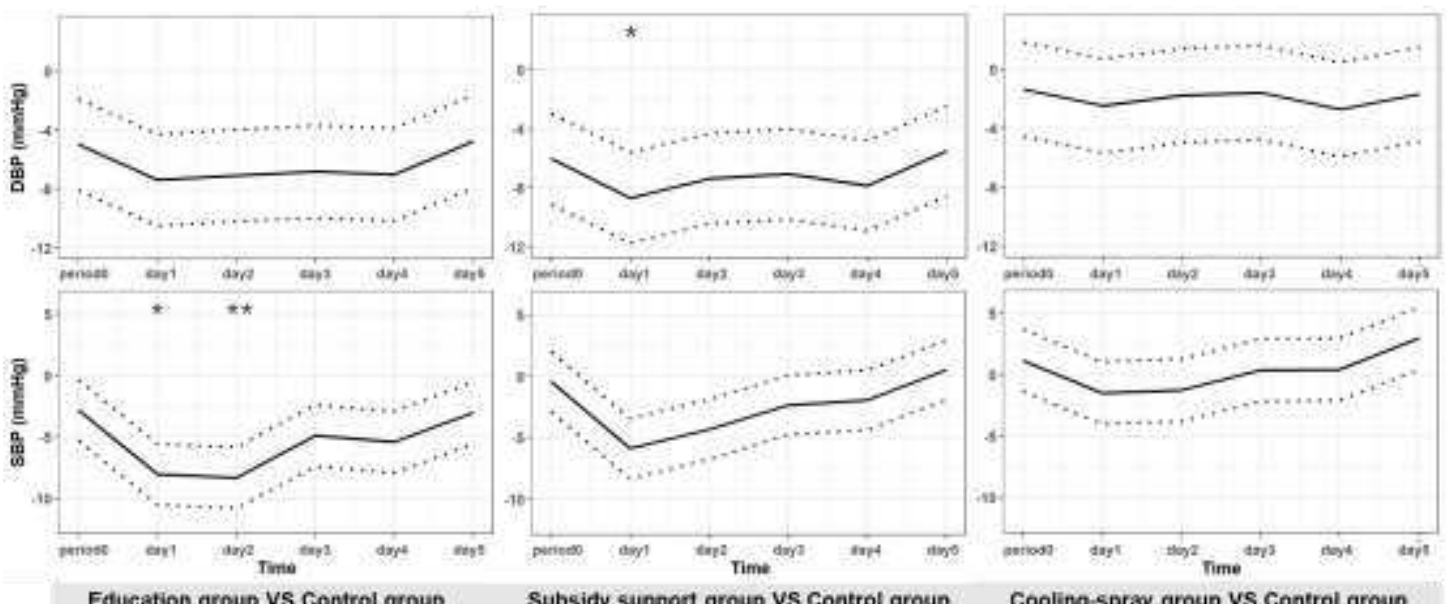

Figure 5 The difference in Blood Pressure between Intervention Groups and Control Group $\left({ }^{*} \mathrm{p}<0.05,{ }^{* *} \mathrm{p}<0.01\right.$, compared with control group, the error bars represent estimate value \pm

The changes in HR in the cooling-spray group were consistently higher than

baseline across all time points, but the trends were not consistent in the subsidy or

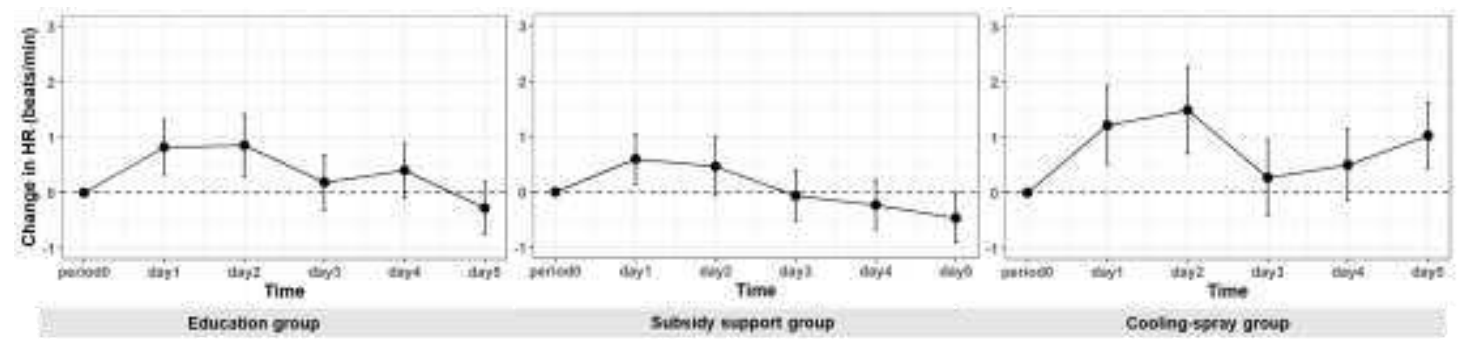

Figure 6 Changes in Heart Rate of Three Intervention Groups from Baseline (period 0)

(The error bars represent estimate value $\pm \mathrm{SE}$ ) 
292 fluctuated during the intervention period, with the largest reduction being -0.20 hours

293 (95\%CI: $-0.40,0.00 ; p=0.06)$ in day 2. Analyses of DSD difference between groups in

294 each period (Figure S3) showed that the DSD levels of the education and subsidy

295 support groups were higher than that of the control group in the five days of intervention.

296 The DSD difference between the education group and the subsidy support group was

297 statistically significant only on day 1.

298 Changes in LSD were minor in three intervention groups, ranging from -0.11 hours

299 to 0.04 hours in the education group, from -0.03 hours to 0.04 hours in the subsidy

300 support group, and from -0.12 hours to -0.18 hours in the cooling-spray group. As a

301 result, changes in TSD of the subsidy support group maintained a continuous increment,

302 while changes in the education group and the cooling-spray group rose in the first few

303 days and then declined. When comparing TSD between groups, TSD in the cooling-

304 spray group was lower than the control group, while TSD in the education and subsidy

305 support group were much higher. However, no significant between-group difference

306 was observed in TSD and LSD during the experiment. 

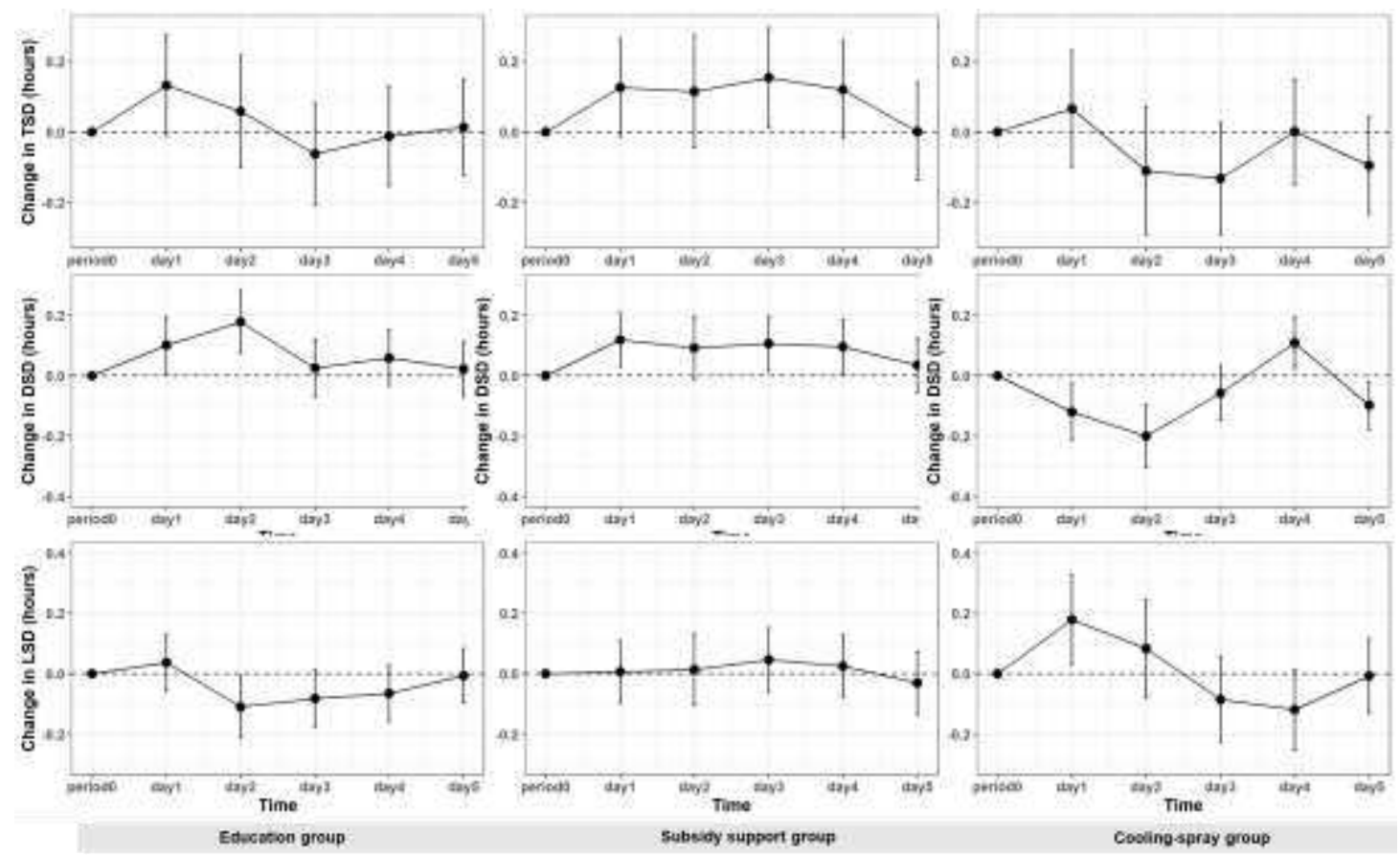

Figure 7 Changes in Sleep Duration of Three Intervention Groups from Baseline (period 0)

(the error bars represent estimate value $\pm \mathrm{SE}$ )

\subsection{Comprehensive Health Sensitivity Index (CHSI)}

Weights of health metrics have been listed in Table 2. On day 1, the score of CHSI

312 in control group (6.93) was significantly higher than education group $(3.72, \mathrm{p}<0.05)$,

313 subsidy support group $(3.50, \mathrm{p}<0.01)$ and cooling-spray group $(4.22, \mathrm{p}<0.05)$, which

314 showed that control group had the highest health sensitivity at the start of the heatwave

315 (Figure 7). However, CHSI in control group declined over time. The score of CHSI decreased from 6.92 to 3.43 on day 5 , indicating the human internal environment in control group had gradually reached a balance. On the second day of the intervention,

318 the scores of the education group and the subsidy support group were still significantly

319 lower than that of the control group $(\mathrm{p}<0.05)$. Though there was no significant difference between control group and cooling-spray group observed, the sensitivity 
321 level of cooling-spray group was lower than control group during experiment.

Table 2 Weights of health metrics

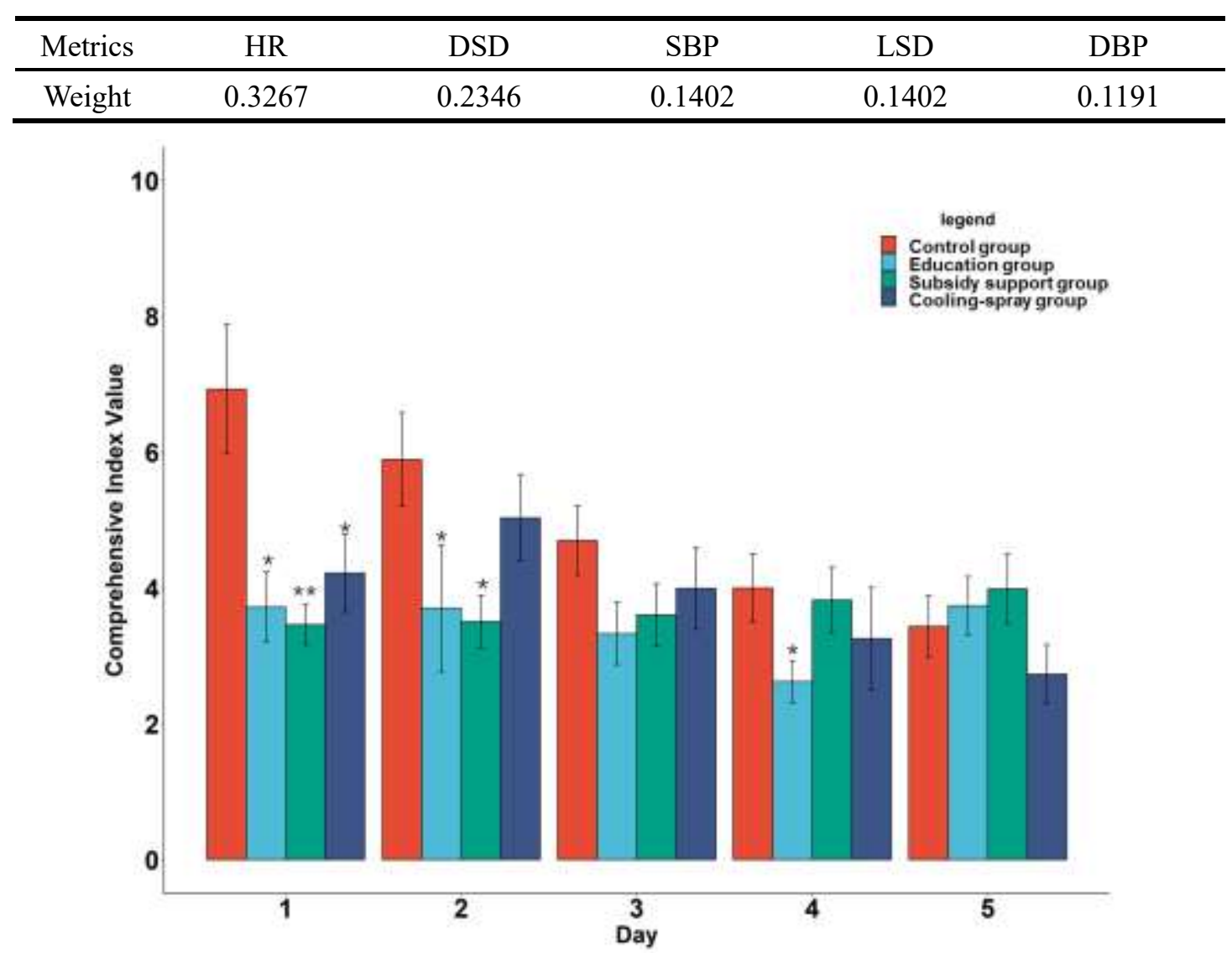

Figure 7 Variations in comprehensive sensitivity Index in four groups along with intervention time $\left({ }^{*} \mathrm{p}<0.05,{ }^{* *} \mathrm{p}<0.01\right.$, compared with the control group, the error bars

represent estimate value $\pm \mathrm{SE}$ )

\section{Discussion}

Based on the comparison between period 0 and high-temperature periods in the control group, health metrics fluctuated greatly when exposed to short-term heat. There was a significant variation in SBP and DSD, which was similar to some previous

331 findings, suggesting that the high-temperature exposure contributed to higher blood 332 pressure and thermal comfort was an essential factor affecting sleep quality[45-47]. 
333 Several studies showed that poor sleep quality might result in increased night-time

334 blood pressure[48]. Nevertheless, the relationship between daily blood pressure and

335 sleep quality needs further study. When exposed to high temperatures, individuals will

336 increase cardiac output and turn on sweat glands to regulate body temperature, which

337 will contribute to blood pressure variation[22]. However, aging is associated with the

338 degenerated ability of cardiovascular adjustments and fluid regulation, resulting in that

339 the elderly might take a higher risk of cardiovascular disease than young adults[18].

340 Because of the effects of human aging on organs and tissues, the elderly have blunted

341 vascular responses and reductions in sweat production, which leads to a limitation of

342 heat dissipation. Trouble falling or staying asleep is another mainly heat-related

343 physical symptom[2]. Findings from other studies also firmed that sleep duration

344 decreased significantly because of the heat exposure[33, 49]. The changes in each

345 metric reflected that the body could be stabilized gradually, consistent with the

346 experiment conducted by Meade[18]. The result of metric weight showed that HR

347 played an essential role in the comprehensive assessment. The studies conducted by

348 Madaniyazi et al (2016) and Carrillo et al (2019) also concluded that heart rate was

349 correlated with heat exposure. Though an increasing trend was observed during the

350 heatwave, there was no significant variation in this study, which was possibly due to

351 the short duration of the experiment.

352 CHSI indicated that education could control the health sensitivity from day 1 to

353 day 4 . In a previous study, it is convinced that there is some mediating effect between 
354 heat exposure and heat-protection action[28]. Being educated, individuals had a higher

355 risk perception on perceived controllability, perceived concern, perceived effect, 356 perceived familiarity[36]. The promotion of risk perception leads to a variety of 357 alternations in heat-protection actions like increased frequency in using cooling 358 equipment, more concern about weather changes, and reduction of the time exposed to 359 sunlight directly. These behaviors enhanced the ability of adaptation to heatwave from 360 psychological and physical aspects and relieved the influence of heatwave[28]. Besides, 361 a study in Licheng showed that education could be considered a worthwhile investment 362 for rural areas than urban areas in the prevalence of heat-related illness[51]. These 363 studies were content to our results, improving the reliability of CHSI.

364 The results of CHSI showed the effectiveness of subsidy support as well. It was 365 found that rural individuals preferred to use fans than air conditioning because of 366 economic issues, which can be solved by subsidy support to a great extent[36, 52].

367 Previous study has shown that subsidy support group was more likely to do home 368 cooling practices after intervention when comparing adaptive behavioral responses in 369 groups[36]. In this circumstance, the willingness and the frequency of using air 370 conditioning increased. As a result, the individual ambient temperature had been 371 reduced to a comfortable level by the usage of air conditioning, which brings about a 372 declined effect of the heatwave on health. However, the effects of subsidy support were 373 significant in the first two periods. One of the reasons could be the limited effects on 374 perception. It is reported that the subsidy support had no significant effect on perceived 
375 effect[36]. Besides, we did not conduct an inquiry of the willingness to pay before the 376 experiments. Therefore, the amount, frequency, and form of the subsidy might be 377 further explored to break the limits.

378 Compared with education and subsidy support, the intervention effect of the 379 cooling-spray is relatively limited. The reasons could be speculated as follows:1) 380 limited coverage area. The equipment was installed in the resident's yard, which means 381 it would be useless when the resident leaves home. 2) limited effect. The outdoor 382 temperature reduction was difficult to be conveyed to indoor. Therefore, the effect of 383 indoor temperature reduction, as well as human thermal comfort, will be limited, when 384 the resident stays in the house. 3) ventilation. Because of the material and the structure 385 of the wall, the yard's ventilated condition was limited. It is reported that fans can be 386 effective as air-conditioning, particularly in humid conditions [22]. Thus, the third 387 reason is that we did not create any wind in the yard, though the humidity had been 388 increased by the equipment. Despite the fact that the air conditioning has an excellent 389 temperature reduction ability, the environmental problems caused by the equipment 390 cannot be regardless [20]. Therefore, it is necessary to explore another economical and 391 environment-friendly method to fight heatwaves.

392 There are still several limitations in our study. First, the number of subjects in our 393 sample group is relatively small, resulting in a limited number of socioeconomic and 394 demographic categories for analysis. From the perspective of verifying the health 395 effects of an intervention, ten subjects in each group are sufficient[53]. For fundamental 
research, a larger number of subjects are required for future experiments. Secondly, the

397 information on occupation and air conditioning use was not collected in the 398 questionnaire; therefore, we cannot further analyze the effect of these two factors on 399 physical metrics. Thirdly, the selected participants connected with the local CDC before 400 might be more concerned about their health. Besides, they have been screened by 401 healthy conditions, limiting the sample's representativity. Next, metrics in period 0 402 represents the average level of metrics without heat exposure, which means that the 403 potential variations during period 0 might have been ignored. Meanwhile, it is difficult 404 to link intervention with specific health endpoints because of the time limitation. 405 Though these metrics are significantly associated with heat-related diseases, further 406 studies should be conducted to confirm the clinically relevant outcomes of interventions.

\section{5. Conclusions}

This study explored effective intervention methods on an individual scale, which 409 supplements the intervention effect from physiological dimension and further validates 410 the results of our previous research. It was found that short-term heat exposure would 411 make effect on blood pressure, heart rate, and sleep duration. Under high temperatures, 412 SBP and DSD were significantly affected in the first two days. For rural elderly, these 413 effects could be efficiently reduced by education, subsidy support, and cooling-spray. 414 Though cooling-spray was not the best method to prevent heat health risk due to its 415 limitation in coverage area and effects, it is deserved to optimize the equipment for its 
416 low carbon emission. A comprehensive health sensitivity evaluation method was

417 proposed to assess the effectiveness of interventions. Compared with previous studies,

418 CHSI was identified as a more practical and propagable approach in health effect

419 assessment. The results indicated that older people should pay more attention to their

420 blood pressure and sleep to prevent themselves from heat-related illnesses. Education

421 and subsidy support made it possible for government and community to provide the

422 vulnerable groups with more targeted help. These findings will provide references for

423 researchers who further investigate the optimal strategies to reduce the health risk of

424 human heat exposure.

425 Ethics approval and consent to participate

The research protocol was reviewed and approved by National Institute of

427 Environmental Health Chinese Center for Disease Control and Prevention. All 428 participants provided written informed consent prior to participation.

429 Consent for publication

$430 \quad$ Not applicable.

431 Availability of data and materials

The datasets used and/or analysed during the current study are available from the 


\section{Competing interests}

435 The authors declare that they have no competing interests.

\section{Funding}

This work was supported by the National Key Research and Development

438 Program of China [2020YFC1807502]; and the Chinese Natural Science Foundation 439 [41822709].

\section{Authors' contributions}

Yujia Huang performed the data curation and wrote the original manuscript. Ting

442 Zhang was a major contributor in writing the manuscript. Jianing Lou was a major

443 contributor to investigation. Peng Wang helped revise the manuscript. Lei Huang was

444 a major contributor in writing the manuscript and acquired fundings. All authors read 445 and approved the final manuscript.

\section{Acknowledgements}

447 This work was supported by the National Key Research and Development 448 Program of China [2020YFC1807502]; and the Chinese Natural Science Foundation 449 [41822709]. 
1. Watts N, Amann M, Arnell N, Ayeb-Karlsson S, Belesova K, Boykoff M, Byass P, Cai W, Campbell-Lendrum D, Capstick S et al: The 2019 report of The Lancet Countdown on health and climate change: ensuring that the health of a child born today is not defined by a changing climate. The Lancet 2019, 394(10211):1836-1878. heat-related health symptoms among community in a tropical city. Sci Total Environ 2021, 782:146611. 3. Brennan M, O'Shea PM, Mulkerrin EC: Preventative strategies and interventions to improve outcomes during heatwaves. Age and Ageing 2020, 49(5):729-732. 4. Bose-O'Reilly S, Daanen H, Deering K, Gerrett N, Huynen M, Lee J, Karrasch S, MatthiesWiesler F, Mertes H, Schoierer J et al: COVID-19 and heat waves: New challenges for healthcare systems. Environ Res 2021, 198:111153.

463 5. Chen R, Yin P, Wang L, Liu C, Niu Y, Wang W, Jiang Y, Liu Y, Liu J, Qi J et al: Association between ambient temperature and mortality risk and burden: time series study in 272 main Chinese cities. BMJ 2018, 363:k4306.

466 6. Anderson GB, Bell ML: Heat waves in the United States: mortality risk during heat waves and effect modification by heat wave characteristics in 43 U.S. communities. Environ Health Perspect 2011, 119(2):210-218.

7. Gasparrini A, Armstrong B: The impact of heat waves on mortality. Epidemiology 2011, 470 22(1):68-73.

471 8. Fouillet A, Rey G, Laurent F, Pavillon G, Bellec S, Guihenneuc-Jouyaux C, Clavel J, Jougla E, 472 Hemon D: Excess mortality related to the August 2003 heat wave in France. Int Arch Occup Environ Health 2006, 80(1):16-24. 9. Lu P, Zhao Q, Xia G, Xu R, Hanna L, Jiang J, Li S, Guo Y: Temporal trends of the association between ambient temperature and cardiovascular mortality: a 17-year case-crossover study. Environmental Research Letters 2021, 16:045004. 10. Zhang A, Hu W, Li J, Wei R, Lin J, Ma W: Impact of heatwaves on daily outpatient visits of respiratory disease: A time-stratified case-crossover study. Environ Res 2019, 169:196-205. 11. Kaiser R, Le Tertre A, Schwartz J, Gotway CA, Daley WR, Rubin CH: The effect of the $\mathbf{1 9 9 5}$ heat wave in Chicago on all-cause and cause-specific mortality. Am J Public Health 2007, 97 (162.

482 12. Song X, Zhang Z, Chen Y, Wang P, Xiang M, Shi P, Tao F: Spatiotemporal changes of global extreme temperature events (ETEs) since 1981 and the meteorological causes. Natural Hazards 2013, 70(2):975-994.

485 13. Han J, Miao C, Duan Q, Wu J, Lei X, Liao W: Variations in start date, end date, frequency 486 and intensity of yearly temperature extremes across China during the period 1961-2017. 487 Environmental Research Letters 2020, in press https://doi.org/10.1088/1748-9326/ab7390.

488 14. Tan J, Zheng Y: Temporal and Spatial Distribution Characteristics of Heat waves in Main 489 Capital Cities of China. METEOROLOGICAL SCIENCE AND TECHNOLOGY 2013, 41(2):347- 
351.

15. Ye D, Yin J, Chen z, Zheng Y, Wu R: Spatiotemporal Change Characteristics of Summer Heatwaves in China in 1961-2010. PROGRESSUS INQUISITIONES DE MUTATIONE CLIMATIS 2013, 9(1):15-20.

16. Yang J, Zhou M, Ren Z, Li M, Wang B, Liu L, Ou CQ, Yin P, Sun J, Tong S et al: Projecting heat-related excess mortality under climate change scenarios in China. Nat Commun 2021, 12(1):1039.

17. Cheng J, Xu Z, Bambrick H, Su H, Tong S, Hu W: Heatwave and elderly mortality: An evaluation of death burden and health costs considering short-term mortality displacement. Environ Int 2018, 115:334-342.

18. Meade RD, Akerman AP, Notley SR, McGinn R, Poirier P, Gosselin P, Kenny GP: Physiological factors characterizing heat-vulnerable older adults: A narrative review. Environment International 2020, 144.

19. Morais L, Lopes A, Nogueira P: Human health outcomes at the neighbourhood scale implications: Elderly's heat-related cardiorespiratory mortality and its influencing factors. Science of the Total Environment 2021, 760.

20. Watts N, Amann M, Arnell N, Ayeb-Karlsson S, Beagley J, Belesova K, Boykoff M, Byass P, Cai W, Campbell-Lendrum D et al: The 2020 report of The Lancet Countdown on health and climate change: responding to converging crises. The Lancet 2021, 397(10269):129-170.

21. Cai W, Zhang C, Suen HP, Ai S, Bai Y, Bao J, Chen B, Cheng L, Cui X, Dai H et al: The 2020 China report of the Lancet Countdown on health and climate change. The Lancet Public Health 2021, 6(1):e64-e81.

22. Pennisi E: LIVING WITH HEAT Studies are probing how heat threatens health-and how to lower the risks. Science 2020, 370(6518):778-781.

23. Huang L, Yang Q, Li J, Chen J, He R, Zhang C, Chen K, Dong SG, Liu Y: Risk perception of heat waves and its spatial variation in Nanjing, China. Int J Biometeorol 2018, 62(5):783-794.

24. Nogueira P, Paixao E, Falcao J: BEHAVIOUR OF THE PORTUGUESE POPULATION DURING HOT SEASONS AND THE HEAT WAVE OF AUGUST 2003. Revista Portuguesa de Saude Publica 2005, 23(2):3-18.

25. Mayrhuber EA-S, Duckers MLA, Wallner P, Arnberger A, Allex B, Wiesboeck L, Wanka A, Kolland F, Eder R, Hutter H-P et al: Vulnerability to heatwaves and implications for public health interventions - A scoping review. Environmental Research 2018, 166:42-54.

26. Ebi KL: Effective heat action plans: research to interventions. Environmental Research Letters 2019, 14(12).

27. Martinez GS, Linares C, Ayuso A, Kendrovski V, Boeckmann M, Diaz J: Heat-health action plans in Europe: Challenges ahead and how to tackle them. Environ Res 2019, 176:108548.

28. Ban J, Shi W, Cui L, Liu X, Jiang C, Han L, Wang R, Li T: Health-risk perception and its mediating effect on protective behavioral adaptation to heat waves. Environ Res 2019, 172:2733.

29. Wang Q, Yu Y, Li Y, Ding Z, Chen X: Evaluation the impact of community intervention on heat wave in Nanjing, China. Chin J Pre Med 2018, 52(2):188-190.

30. Masato G, Bone A, Charlton-Perez A, Cavany S, Neal R, Dankers R, Dacre H, Carmichael K, 
533 In England: A Proof-of-Concept Using Temperature-Mortality Relationships. PLoS One 2015, 534 10(10):e0137804.

535 31. Matzarakis A, Laschewski G, Muthers S: The Heat Health Warning System in GermanyApplication and Warnings for 2005 to 2019. Atmosphere 2020, 11(2). Temperature, Heart Rate and Blood Pressure in Chinese Adults: Effect Modification by Individual Characteristics. Sci Rep 2016, 6:21003. 33. Kim Y-M, Kim S, Cheong H-K, Ahn B, Choi K: Effects of heat wave on body temperature and blood pressure in the poor and elderly. Environmental health and toxicology 2012, 27:e2012013-e2012013.

543 34. Jay O, Capon A, Berry P, Broderick C, de Dear R, Havenith G, Honda Y, Kovats RS, Ma W, Malik A et al: Reducing the health effects of hot weather and heat extremes: from personal cooling strategies to green cities. The Lancet 2021, 398(10301):709-724. 35. Takahashi N, Nakao R, Ueda K, Ono M, Kondo M, Honda Y, Hashizume M: Community trial on heat related-illness prevention behaviors and knowledge for the elderly. Int $J$ Environ Res Public Health 2015, 12(3):3188-3214. 36. Lou J, Ban J, Zhang T, Wang P, Wu Y, Huang L, Li T, Bi J: An intervention study of the rural elderly for improving exposure, risk perception and behavioral responses under high temperature. Environmental Research Letters 2021, 16(5). Multi-source Data: A Case Study of the Yangtze River Delta Region, China. Journal of GeoInformation Science 2017, 19(11):1475-1484. CHARACTERISTICS OF SUMMER HEATWAVES IN JIANGSU-ZHEJIANGSHANGHAI REGION DURING 1961-2010. Resources and Environment in the Yangtze Basin 2016, 25(3):506-513. 39. Chen K, Huang L, Zhou L, Ma Z, Bi J, Li T: Spatial analysis of the effect of the 2010 heat wave on stroke mortality in Nanjing, China. Sci Rep 2015, 5:10816. 40. Guo Y, Gasparrini A, Armstrong BG, Tawatsupa B, Tobias A, Lavigne E, Coelho M, Pan X, Kim H, Hashizume M et al: Heat Wave and Mortality: A Multicountry, Multicommunity Study. Environ Health Perspect 2017, 125(8):087006. 41. Wang J, Meng B, Pei T, Du Y, Zhang J, Chen S, Tian B, Zhi G: Mapping the exposure and sensitivity to heat wave events in China's megacities. Sci Total Environ 2021, 755(Pt 1):142734. 42. Wei J, Mi Y, Li Y, Xin B, Wang Y: Factors associated with awareness, treatment and control of hypertension among 3579 hypertensive adults in China: data from the China Health and Nutrition Survey. BMC Public Health 2021, 21(1):423. 43. Huang L, Huang Y, Liu P, Wang G, Bi J: Research on regional comprehensive environmental risk assessment method system. China Environmental Science 2020, 40(12):54685715474.

572 44. Qu C, Bi J, Huang 1, Li F, Yang J: Dynamic Comprehensive Evaluation on Regional 573 Environmental Risk. Acta Scientiarum Naturalium Universitatis Pekinensis 2010, 46(3):477-482. 
45. Guo $\mathrm{P}$, Tang M: The effect of high temperature on human cardiovascular system and blood sugar. Chin J Convalescent Med 2015, 24(2). 46. Zhou X, Liu J: High-temperature Operation on the blood pressure and blood lipids of workers in Iron and Steel Enterprises of Urumqi. Ind Hlth\& Occup Dis 2018, 44(1). 47. Zhang N, Cao B, Zhu YX: Indoor environment and sleep quality: A research based on online survey and field study. Building and Environment 2018, 137:198-207. 48. Tamura $\mathrm{K}$, Uchida $\mathrm{K}$, Ishigami $\mathrm{T}$ : An interesting link between quality of sleep and a measure of blood pressure variability. J Clin Hypertens (Greenwich) 2021, 23(2):331-333. 49. Hendel M, Azos-Diaz K, Tremeac B: Behavioral adaptation to heat-related health risks in cities. Energy and Buildings 2016:S0378778816317212. 50. Carrillo AE, Flouris AD, Herry CL, Notley SR, Macartney MJ, Seely AJE, Wright Beatty HE, Kenny GP: Age-related reductions in heart rate variability do not worsen during exposure to humid compared to dry heat: A secondary analysis. Temperature (Austin) 2019, 6(4):341-345. 51. Li J, Xu X, Wang J, Zhao Y, Song XP, Liu ZD, Cao LN, Jiang BF, Liu QY: Analysis of a Community-based Intervention to Reduce Heat-related Illness during Heat Waves in Licheng, China: a Quasi-experimental Study. Biomed Environ Sci 2016, 29(11):802-813.

590 52. Wu Y, Lou J, Li T, Wang Q, Ban J, Sun X, Huang L: Analysis of Individual Difference in 591 Rural Vulnerable Groups'Risk Perception of Heat Waves and their Protective Behavior. 592 journal of Environmental Hygiene 2020, 10(1):25-30.

593 53. Deng Y, Cao B, Liu B, Zhu Y: Effects of local heating on thermal comfort of standing people in extremely cold environments. Building and Environment 2020, 185. 


\section{Supplementary Files}

This is a list of supplementary files associated with this preprint. Click to download.

- supportinginformation.docx 